\title{
Commentary: Let's get rich-The use of hydrogen-rich solution for lung preservation
}

\author{
Benjamin Wei, MD, and Alisha Jiwani, MD, MPH
}

\footnotetext{
From the Division of Cardiothoracic Surgery, Department of Surgery, University of Alabama-Birmingham Medical Center, Birmingham, Ala.

Disclosures: Authors have nothing to disclose with regard to commercial support

Received for publication Sept 26, 2019; revisions received Sept 26, 2019; accepted for publication Sept 27, 2019; available ahead of print Oct 28, 2019.

Address for reprints: Benjamin Wei, MD, University of Alabama-Birmingham Medical Center, Zeigler Research Building 701, 619 19th St S, Birmingham, AL 35294 (E-mail: bwei@uabmc.edu).

J Thorac Cardiovasc Surg 2020;159:2119-20

0022-5223/\$0.00

Published by Elsevier Inc. on behalf of The American Association for Thoracic Surgery

https://doi.org/10.1016/j.jtcvs.2019.09.129
}

Overall survival after lung transplantation is lower than that after other solid-organ transplants, in part because of primary graft dysfunction secondary to ischemia-reperfusion injury. Early graft failure is implicated as the main cause of death in approximately $30 \%$ of lung transplant recipients. Although it is well established that use of the optimal preservation solution is critical for donor organ quality, investigators continue to work on trying to improve lung preservation relative to the current static cold-storage method. ${ }^{1}$ These efforts include ex vivo lung perfusion and the administration of various compounds during the time between procurement and implantation. ${ }^{2}$ One way of minimizing ischemia-reperfusion injury that investigators have studied involves inflating the lungs with gas containing hydrogen $\left(\mathrm{H}_{2}\right)$ during either storage or implantation. ${ }^{3,4}$ In their article in this issue of the Journal, Saito and colleagues ${ }^{5}$ evaluate the protective effects of a hydrogen-rich preservation solution against ischemia reperfusion injury in Lewis rats undergoing orthotopic left lung transplantation. They ultimately conclude that the addition of hydrogen to preservation solution decreases ischemia-reperfusion injury to donor lungs, representing a relatively safe and easy method to achieve decreased primary graft dysfunction that could potentially be applied to human lung transplantation in the future.

Saito and colleagues ${ }^{5}$ found that adding dissolved hydrogen to Perfadex solution (XVIVO Perfusion AB, Göteborg, Sweden) led to significantly lower levels of inflammatory cytokines and 8-hydroxy-2'-deoxyguanosine (an oxidative stress marker), as well as to reduced vascular endothelial dysfunction. These levels correlated with higher levels of expression of heme oxygenase- 1 by way of the nuclear factor erythroid 2-related factor antioxidant pathway. Additional benefits conferred by the addition of hydrogen to the preservation solution include higher dynamic pulmonary compliance, lower peak airway pressures, and better oxygenation levels. The hydrogen concentration was $0.8 \mathrm{ppm}$ in the solution, which was stored in an aluminum bag to prevent diffusion of the solubilized hydrogen.

\section{References}

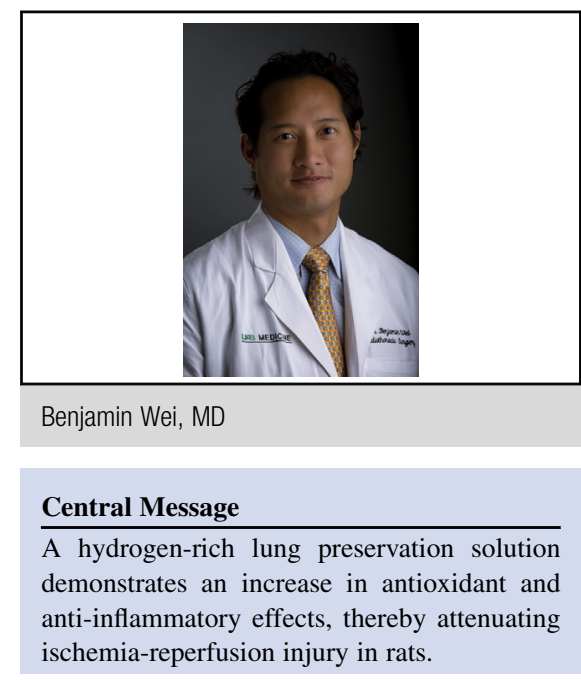

See Article page 2110.

Currently, one cannot readily buy a hydrogen-infused Perfadex bag; the solution must be made independently. Saito and colleagues ${ }^{5}$ do provide detailed instructions on their preparation and administration techniques. It is not clear from their study whether or not the addition of hydrogen to Perfadex in the perfusion phase, the storage phase, or both phases was responsible for the benefits seen.

As the first study to examine the effects of preservation with hydrogen-rich solution during cold ischemia in an experimental lung transplant model, Saito and colleagues ${ }^{5}$ propose a potentially promising therapy to mitigate lung ischemia-reperfusion injury. In light of this compelling evidence, the findings presented justify additional investigation with larger sample sizes in the rat model and potentially safety and then efficacy studies in humans to verify the trends observed. Successful adoption of hydrogen-enriched preservation solution could significantly decrease the incidence of primary graft dysfunction, improve survival rates, and possibly extend permissible ischemic time. Moreover, because the availability of suitable donors is limited, the use of marginal donor lungs is gaining favor. It is certainly conceivable that the use of a more favorable organ preservation solution could increase our ability to use marginal donor lungs safely.

1. Nath DS, Walter AR, Johnson AC, Radosevich DM, Prekker ME, Herrington CS et al. Does Perfadex affect outcomes in clinical lung transplantation? J Heart Lung Transplant. 2005;24:2243-8. 
2. Wagner CE, Pope NH, Charles EJ, Huerter ME, Sharma AK, Salmon MD, et al, Ex vivo lung perfusion with adenosine A2A receptor agonist allows prolonged cold preservation of lungs donated after cardiac death. J Thorac Cardiovasc Surg. 2016;151:538-45.

3. Zhang G, Li Z, Meng C, Kang J, Zhang M, Ma L, et al. The anti-inflammatory effect of hydrogen on lung transplantation model of pulmonary microvascular endothelial cells during cold storage period. Transplantation. 2018;102:1253-61.
4. Kawamura T, Huang CS, Tochigi N, Lee S, Shigemura N, Billiar TR, et al. Inhaled hydrogen gas therapy for prevention of lung transplantinduced ischemia/reperfusion injury in rats. Transplantation. 2010;90: 1344-51.

5. Saito M, Chen-Yoshikawa TF, Takahashi M, et al. Protective effects of a hydrogenrich solution during cold ischemia in rat lung transplantation. J Thorac Cardiovasc Surg. 2020;159:2110-8. 